\title{
Mediterranean Fruits: Ancient History and Modern Promise
}

\author{
Ed Stover ${ }^{1}$ \\ USDA/ARS, NCGR, One Shields Avenue, Davis, CA 95616
}

Historically, several fruits were extremely significant to the people living in the Mediterranean region, and this importance was reflected in frequent mention of these fruits in the holy books of major world religions of Mediterranean origin. Grapes (Vitis vinifera) continue to be one of the most important fruits of commerce, and receive much attention within the U.S. horticultural community. In contrast, the other Mediterranean fruits of historical importance have received relatively little attention within the United States. Several of these fruits are now being viewed with renewed interest. In this workshop, a historical overview was provided to place Mediterranean fruits into cultural context. This was followed by detailed discussion of dates, figs, olives, and pomegranates, to provide interested horticulturists and lovers of fruits with an understanding of the fascinating biology of these crops, an overview of current cultivars, and these fruits' place in modern commerce. Recordings (DVD) of these presentations may be purchased at www.ashs. org $/$ shop $/$ product.php? productid $=16789 \&$ cat $=103$ \&page $=1$.

The workshop ended with a tasting of these fruits and their products, and it is hoped that the interested reader will also pursue such opportunities.

The U.S. Department of Agriculture, Agriculture Research Service, National Clonal Germplasm Repository (NCGR) in Davis, $\mathrm{CA}$, is home of the national collections of most Mediterranean-adapted fruits and nuts (including fig, olive, and pomegranate), whereas the NCGR at Riverside, CA, maintains the dates and citrus. Our missions are to acquire, preserve, characterize, and distribute germplasm resources of these crops. We are committed to acquiring additional material and are very interested in learning of such opportunities, with a special interest in protecting collections that may otherwise be lost. It is National Plant Germplasm System (NPGS) policy to distribute plant material, free of charge, to research interests around the world (see the NPGS repository webpage www. ars-grin.gov/npgs/holdings.html).

This workshop was presented by the American Pomological Society (APS), an organization affiliated with the American Society for Horticultural Science (ASHS). The American Pomological Society (APS) predates ASHS, having been founded in 1848 , and is considered to have given birth to the younger and currently much larger organization. Past APS presidents include Liberty Hyde Bailey (1919-1924). The American Pomological Society meets annually with ASHS and holds both a concurrent workshop and an evening educational meeting that provide interesting information and an opportunity to taste fruits and their products, as a celebration of our shared love for fruit, their associated science, and their lore.

The American Pomological Society publishes the Journal of the American Pomological Society, which contains refereed articles on a wide range of fruit-related topics. The society website can be found at http:// americanpomological.org/. The American Pomological Society provides several annual awards: the Wilder Medal to an individual or organization for distinguished service and contributions to the advancement of pomological science, including developing outstanding fruit cultivars; the U.P. Hedrick Award for the best Journal of the American Pomological Society paper submitted by horticulture students; and the Shepard Award for best scientific paper published in the Journal of the American Pomological Society the previous year. If you are a fruit-loving horticulturist, please participate in the next APS meeting! 